\title{
Use of indigenous stone play in child psychological assessment
}

Nerine Daphné Odendaal and Mokgadi Moletsane

\begin{abstract}
The purpose of the study was to investigate an indigenous stone play called Masekitlana, as a projection technique in child psychological assessment. A qualitative research approach, guided by an interpretivist epistemology, was applied. An intrinsic case study design was employed with a purposively selected female Sesotho child that is 7 years of age as participant. Data collection methods consisted of interviews, Masekitlana play sessions, a reflective journal and observations. Findings suggest that the participant in her play projected several issues important to her psychosocial wellbeing: food and nutrition, conflict among community adults and peers, effects of poor infrastructure, belief system and resilience. The interview with the participant's mother validated the substantive findings from stone play thematic analysis. Masekitlana appears a useful technique in child psychological assessment in an indigenous setting.
\end{abstract}

\section{Introduction}

The development of psychology in South Africa has largely been dominated by Western intellectual and methodological trends (Painter \& Terre Blanche, 2004). Furthermore, psycho- logical assessment in South Africa developed in an environment characterised by unequal distribution of resources based on racial categories such as Black, Coloured, Indian and White (Foxcroft \& Roodt, 2001). Inevitably, the development of psychological assessment reflected the racially segregated society in which it evolved.

According to the Health Professions Act 56 of 1974, the Professional Board for Psychology of the Health Professions Council of South Africa (HPCSA) is mandated to protect the public and to guide the profession of psychology, (Foxcroft \& Roodt, 2001).

South Africa is characterised by cultural and linguistic diversity (Goduka \& Swadener, 1999), and Mental Health Practitioners have opportunities to assess clients from diverse social backgrounds. In this regard, Anastasi and Urbina (1997) suggest that the training of the examiners should incorporate knowledge of one or more dissimilar cultures, with special attention to the likely cultural effects on the behaviour and development of individuals.

Assessing children of African origin and culture in South Africa requires culturally appropriate assessment media for indigenous South African settings. South Africa is a multicultural society. There is a compelling need for assessments responsive to the experience of indigenous African children (Kekae-Moletsane, 2008). This study investigated the use of Masekitlana, which is an indigenous stone play approach to psychological assessment.

Masekitlana Stone Play: A Description. Masekitlana is de- scribed by KekaeMoletsane (2008) as a traditional indigenous South African game which is usually played by children, especially in rural areas and townships. During Masekitlana play children express themselves verbally while playing with small stones. Masekitlana 
develops children's communication and coping skills and serves as a therapeutic technique.

Masekitlana does not have specific rules and structure. It is accommodative in that all children are comfortable to play the game, including those who are shy and withdrawn. Players only need two or more small stones. Players hit the stone with the other stone several times while relating their imagined stories (Kekae-Moletsane, 2008).

\section{Goals of the Study}

The goal of the study was to investigate prospects for Masekitlana, to serve as a projection technique during psycho- logical assessment with a Sesotho speaking child. The intention was not to select a child with a particular psychological disorder, but rather to investigate and to get an understanding of the assessment possibilities and benefits when using Masekitlana as a psychological assessment technique with children. The following question guided the research:

How can Masekitlana play themes be interpreted as projective data in psychological assessment with a child?

\section{Method}

\section{Research Design}

The study was a single case design (Merriam, 2002) and guided by an interpretivist paradigm. Merriam, in Ary, Jacobs, Razavieh \& Sorensen (2006) states that the interpretivist paradigmatic viewpoint has to do with how individuals construct and give meaning to their worlds. In this study the researchers were interested in the participant's projections while playing Masekitlana and what she meant by her projections. It was a case study that focused on a participant of seven years of age living in an informal settlement who played Masekitlana on a regular basis.

\section{Case Description}

The participant was a seven year old Sesotho girl. She was not previously diagnosed with any particular disorder and had never been for psychological assessment. The participant was from a poverty-stricken area and stayed with her mother in an informal settlement. Her parents were not living together because her father used to verbally abuse her mother especially when he was drunk. According to the participant's mother, the participant witnessed her father's outrage, but was never physically abused by her father.

The father did not materially support the participant or family in any way. The only income that the participant and her unemployed mother received was a government 'Child Support Grant' of R210 (South African Rand) per month. The participant's mother was in poor health. The family received a food parcel every month from the Community Centre that included some vegetables, supplements, porridge, and other basic foods.

The housing backlog in South Africa coupled with a short- age of housing subsidies means that for many South Africans there is no alternative but to live in informal housing and shack settlements (Richards \& O'Leary, 2006). The family lived in a one-roomed house of approximately 4 meters $\times 4$ metres in size, with no water supply in-house. Furthermore, their neighbourhood was extremely congested and 
polluted, with heaps of rubbish in the streets. The participant was a high achieving learner at school. We decided to learn more about the participant's world view by using a child friendly traditional narrative play approach: Masekitlana. Narrative approaches have substantial evidence for their appropriateness in typical African settings.

\section{Data Collection}

Data were collected using stone play with unstructured interviews with the participant and her mother. In addition, a self-reflective journal was maintained by the researchers through keeping written records of her observations, questions and thoughts during the research process.

Masekitlana stone play was the primary data collection method and probe questions engaged the participant in telling play narratives that portrayed her life in the family and community settings. We observed the participant play Masekitlana over five sessions. The participant's mother provided information regarding the historical background, the developmental mile- stones of the participant, as well as the living conditions.

\section{Data Analysis}

We analyzed and interpreted the participant's projections of her Masekitlana play using qualitative thematic analyses. We assumed the Masekitlana story account would provide a window into the child's psychological state.

\section{Ethical Considerations}

We obtained permission for the study from both the participant and her mother. In the process, we explained the research process to them. We specifically informed the participants of their right to withdraw from the study if they wished so. We debriefed participants at the end of the assessment sessions.

\section{Findings and Discussion}

Several themes emerged from the Masekitlana play story sessions: lack of food in the context of poverty, security and safety needs, environmental factors, guiding belief systems and resilience. The information obtained during Masekitlana play sessions correlated with the information obtained from the participant's mother. The pertinent themes are discussed below.

\section{Lack of Food and Poverty}

Through playing Masekitlana the child psychologically got in touch with her perpetual need for food and a continuous hunger, evident from the repeated mention of 'they ate, they ate, they ate'. The lack of food that she experienced was also indicated by 'I wasn't full that day'. Food is one of the basic needs in hu- mans. In developing countries there are millions of children living under severe conditions of poverty who do not have enough food (Donald, Lolwana \& Lazarus, 2004). This applies to the participant in this study.

Due to poverty, the participant and her mother received a monthly food parcel from a Community Centre with basic products like porridge, mealie-meal and vegetables which come from the garden of the community centre. The struggle to have enough food was persistent and continuous in the participant's life. It was apparent from the 
Masekitlana play stories that the participant was preoccupied with food and nutrition needs.

It was also evident that the participant was aware of food re- sources in the local environment. For instance, during Masekitlana play session, she mentioned that she wanted to eat 'Sphahlo'. Sphahlo can be described as a sandwich with fried eggs and polony spiced with atjar and various other ingredients chosen by the individual who buys it at Spaza shops in the town- ships. Her preference for Sphahlo was to a large extent shaped by its availability in her neighbourhood. Sphahlo is popular among people living in townships and informal settlements.

\section{Security and Safety Needs}

Personal safety in the neighbourhood was a major concern to the participant. For example, the child participant mentioned that two adults fought over the poisoning of rats in their homes. The fulfilment of children's safety needs is important to their sense of security (Mwawenda 2004, p. 240). Another contributing factor concerning the projection of lack of safety could be that the participant, witnessed her mother being physically abused by her father.

The child participant reported experiencing tension and conflict in her peer group. This was suggested when she said: 'I will beat you! Fooh !!' in a loud voice while playing Msekitlana. She continued by saying: Do you think you can beat me?' Conflict was also suggested by 'she had a black eye, black eye, be-cause one beats this one, and then she has a black eye'. It would seem that peer conflict in the community was often physical, as borne out by statements about group attacks (e.g.,

'We are going to hit him' and 'We will get you back, we are not afraid of you and then, then he said I'm not afraid of you'.

\section{Environmental Issues}

The child participant projected about the transport used in her community, and hygiene issues. The participant and her friends made use of taxis mostly (They took a taxi'; 'A taxi took them home)'.and personally owned cars were only used rarely 'we're in the car (with excitement).'

The child participant was aware of hygiene. Very often in her stories she mentioned that 'they bathed', 'I bathe before I go to school. It was important for the participant to look clean especially for important occasions like a car ride ('I'm going to bath as well.... we gonna go with our car') or when having meals ('They washed their hands and the apples'). Some of the hygiene learning may have been from the local clinic which provided community education on the importance of hygiene.

The child participant had a sense of community and belongingness. In her Masekitlana play stories, she said she was "in a society". Her community had supportive social networks for all manner of resources including short-term money borrowing/lending, and also exchange of basic resources like paraffin or cooking oil. This can explained by the "Ubuntu" principle, an indigenous philosophy which promotes communality, oneness or cooperation and sharing is evident or present (Ed- wards, 2000; Nefale \& Van Dyk, 2003:62) 


\section{Belief Systems}

In one of her Masekitlana play stories, the child participant spoke about a sangoma whom she referred to as the 'Naka'. She is afraid of 'Naka', who creates anxiety in her life. We realised that the participants wanted to say "Ngaka" which is a Sesotho word for sangoma or traditional healer. There was a sangoma training centre close to the participant's school.

Thornton (2009) defines sangomas as people that offer a wide range of counselling, divination/diagnostic, medical and other services. The special art of the sangoma is rarely directed simply at organic causes of physical disease. Furthermore, Thornton (2009) states that sangomas prepare muti (medicine) to protect clients from theft, witchcraft, infection, loss of love, unemployment, losing deals, accidents for instance. They alleviate anxiety and depression, assist with decisions clients need to make and find stolen objects. Hanks (2008) discovered that an overwhelming majority of South Africans still rely on sangomas to provide ailments for emotional and psychological problems. Pervasive feelings of fear that are elicited by the 'Ngaka' are suggested by her saying things like 'they see the Naka, yô !' 'Yô, they were scared'. It appeared that the participant had ambivalent feelings about the Ngaka in that she perceived the Ngaka's demeanour to be threatening. This was suggested by a question during a Masekitlana play session in which she said to her imaginary friend;

'where do you come from?' and the dishonesty with which the child participant responded when answering; 'I, I hit her, she took me to see the Naka, but she didn't tell me that Naka bites. Naka bit me (demonstrates on the tip of her finger)'. The child participant's friend was bitten by the Ngaka: 'Dinewo is bitten by the Naka'. The consequences when the Ngaka has bitten a person are negative and apparently the vic- tim gets sick. This is suggested by:They cried, and prayed that

Dinewo gets well; Oh, my Dinewo !! they cried.

However, she also expressed an interest to be friends with Dinewo. For instance, in one of her stories, she would invite a friend to visit a Ngaka ('Now, friend let's go and see the Naka'). Children of that age are inquisitive in nature and want to explore their life worlds even if it can be risky at times. The participant child appeared aware of the social sanctions that apply to children to visit Ngakas.

\section{Resilience}

The child participant displayed resilience by managing to cope with everyday life situations in her environment. Resilience is defined by Dyer and McGuiness (1996) as a process whereby people bounce back from adversity and go on with their lives. For instance, the child participant displayed confidence and initiated play activities with friends and other community members.

She had internal and external protective factors which aided her to be resilient. Her mother was very much involved in her life and was concerned about her child's wellbeing. The child participant's superior performance in school suggested she was able to adapt to her living conditions to be successful as a learner. Erikson states in Pearson, Russ \& Cain Spannagel (2008) that the child uses play to gain mastery over traumatic events and everyday conflicts, which was the case in this study. 


\section{Limitations, Recommendations and Suggestions for Further Study}

The limitation of this study is that it focuses on only one child, and also that it is highly speculative in its interpretations. We acknowledge other methods to explore psychosocial dynamics in indigenous children that may have a stronger evidence base. The standardisation of Masekitlana as an assessment medium is suggested.

\section{Conclusion}

Masekitlana play appeared to enable the study child to reflect on her life situations, thereby revealing the related dynamics. Masekitlana has potential as an assessment procedure to understand indigenous children in their own settings. 


\section{References}

Allen, J., \& Dana, R. H. (2004). Methodological issues in cross-cultural and multicultural Rorschach Research. Journal of Personality Assessment, 82(2), 189-206.

Anastasi, A., \& Urbina, S. (1997). Psychological testing, (7th ed.). New York, NY: Prentice Hall.

Claassen, N. C. W. (1997). Cultural differences, politics and test bias in South Africa. European Review of Applied Psychology, 47(4), 297-307.

Donald, D. Lazarus, \& S. Lolwana, P. (2004). Educational Psychology in Social Context. Cape Town, South Africa: Oxford University Press.

Dyer, J. G., \& McGuinness T. M. (1996). Resilience: Analysis of the concept. Archives of Psychiatric Nursing, 10(5), 276-282.

Edwards, S. D. (2000). Developing community psychology in Zululand- South Africa. In S. N. Madu, P. K. Baguma, \& A. Pritz (Eds.), Psychotherapy and African reality (pp.149-159). Pietersburg, South Africa: UNN Press.

Foxcroft, C., \& Roodt, G. (Eds.) (2001). An introduction to psychological assessment in the South African context. Cape Town, South Africa: Oxford University Press.

Geldard, K., \& Geldard, D. (2005). Counseling Children. A practical introduction (2nd ed.). Los Angeles, CA: Sage.

Hall, G. C., \& Maramba, G. G. (2000). In search of cultural diversity: Recent literature in cross-cultural and ethnic minority psychology. Cultural Diversity and ethnic minority psychol- ogy. Washington, DC: American Psychological Association, Educational Publishing Foundation.

Hanks, T. L. (2008). The Ubuntu Paradigm: Psychology's next force? Journal of Humanistic Psychology, 48(1), 116-135.

Huysamen, G. K. (1980). Psychological testing in South Africa. Pretoria, South Africa: Academia.

Kekae-Moletsane, M. (2008). Masekitlana: South African traditional play as a therapeutic tool in child psychotherapy. South African Journal of Psychology, 38(2), 367-375.

Merriam, S. B. (2002). Introduction to Research in Education. In D. Ary, L. Jacobs, A. Razavieh, \& C. Sorenson (Ed.), Introduction to Research in Education (pp. 528582). Edmonton, Canada: Thomson Wadsworth.

Mwawenda, T. (2004). Educational psychology: An African perspective ca: Paarl Print.

Nefale, M. C. \& Van Dyk, G. A. J. (2003). Ubuntu therapy - A psychotherapeutic model for African clients. In N. S. Madu (Ed.), Contributions of psychotherapy in Africa (pp.76-99). Sovenga, South Africa: UNIN Press. 
Painter, D. \& Terre Blanche, M. (2004). Critical psychology in South Africa: Looking back and looking ahead. South African Journal of Psychology, 34(3), 520-543.

Pearson, B. L., Russ, S. W., Cain-Spannagel, S. A. (2008). Pre- tend play and positive psychology: Natural companions. The Journal of Positive Psychology, 3(2), 110-119.

Richards, R., O'Leary, B. \& Mutsonziwa, K. (2007). Measuring quality of life in informal settlements in South Africa. Social Indicators Research Journal, 81(2), 375388.

Thompson, C. L. \& Henderson, D. A. (2007). Counseling children (7th ed.). Crawfordsville, CA: Thomson Brooks / Cole.

Thornton, R. (2009). The transmission of knowledge in South African traditional healing. Africa, $17-34$. 